BMJ Surgery, Interventions, $\&$ Health Technologies

\section{Precision prostatectomy: reconciling functional and oncological outcomes}

To cite: Neal D. Precision prostatectomy: reconciling functional and oncological outcomes. BMJ Surg Interv Health Technologies 2019;1:e000015. doi:10.1136/ bmjsit-2019-000015

Received 18 June 2019 Accepted 11 July 2019

\section{Linked}

http://dx.doi.org/10.1136/ bmjsit-2019-000002

\section{Check for updates}

(C) Author(s) (or their employer(s)) 2019. Re-use permitted under CC BY-NC. No commercial re-use. See rights and permissions. Published by BMJ.

Nuffield Department of Surgical Sciences, Oxford University, Oxford, UK

Correspondence to Professor David Neal; david.neal@nds.ox.ac.uk
Surgical oncologists need constantly to balance delivering the best long-term cancerfree outcomes against preserving function and facilitating rapid recovery. Minimally invasive surgical techniques and alternative methods of tissue ablation such as high intensity focused ultrasound (HIFU), radio-frequency ablation, cryotherapy and laser-based photodynamic therapies are being tested to address this need. One major question is which men require radical treatment because without it they are at risk of progression, metastasis and death, and which men might be managed by careful monitoring. Another question addressed by this paper is whether some men with low or intermediate risk prostate cancer (PC) might wish to have surgical treatments which have an increased risk of leaving tumour behind, but which have better side effect profiles. The crucial question they raise, however, is whether the trade-off between better quality of life and the risks of leaving some residual local tumour can be safely calibrated. The reason this is important is because evidence from meta-analyses shows that positive margins are associated with increased rates of biochemical recurrence (by $35 \%-50 \%),{ }^{1}$ in men having standard radical prostatectomy, although in T2 Gleason 6 disease, the increased risk of biochemical recurrence may be modest.

When new techniques are developed, researchers have an obligation to determine that they are safe and effective and that the process of introduction does not harm patients. These challenges are acute in the management of PCs. Sood and colleagues from the Vattikuti Urology Institute at the Henry Ford Hospital in Detroit describe in this issue of the journal a modification of existing techniques of robotic-assisted laparoscopic prostatectomy (RALP) for the treatment of localised PC. Do they pass the test?

Current evidence suggests that mp-MRI and targeted biopsy coupled with systematic biopsy is the most accurate way of identifying men with significant cancers at diagnosis. ${ }^{2-4}$ But how accurate are such approaches in picking up additional clinically significant cancers (Gleason Group $\geq 2$ ) within a prostate known already to harbour a cancer? While the precise figure is open to debate, it is clear that men with clinically significant disease frequently harbour multifocal cancers. It is also clear that many of these cancers are missed by current diagnostic approaches and are distant from the 'index' cancer. ${ }^{56}$ Furthermore, it is now clear that within the prostate there are significant 'field effects' and that while some cancers have evolved from a single clone, others are truly polyclonal in origin. ${ }^{7}$ For these reasons, reservations continue to exist around the use of focal therapy where only the cancer(s) which can be seen (the index or dominant lesion) are treated. Conversely, the rationale for testing conservative approaches is that Active Surveillance is proven to be a valid approach for Gleason Grade Groups 1 and 2, since most low risk and intermediate risk PCs do not cause symptoms, metastasis and death within a 10-year time frame ${ }^{8}$ and many low and intermediate risk cancers stay of the same grade over time. ${ }^{9}$ However, it also clear that dedifferentiation can occur over time in some men. ${ }^{1011}$

Progression and death rates in such men at 10 years are extremely low following surgery, radiotherapy and active surveillance ${ }^{8}$ and biochemical recurrence following surgery in Gleason Groups 1 and 2 is $20 \%$ at 10 years, $^{12} 13$ so measurement of safety for new approaches can only be defined in the longterm. Nevertheless, increased rates of early cancer recurrence are concerning. Another open biological question is if creating a wound within the prostate either by HIFU or partial prostatectomy, resulting in an environment rich in cytokines and growth factors, might actually promote long-term cancer growth if malignant cells are left behind. ${ }^{14}$

Menon and colleagues have tested the idea of carrying out a standard robotic-assisted 
nerve-sparing radical prostatectomy on the side of the main lesion and carrying out a fascial-preserving approach on the contralateral side in a selected group of men who might have been suitable for HIFU/focal therapy. The purpose was to remove all the prostate and all the cancer on the side of the dominant lesion; on the other side, the fascia and a 'thin rim of prostate' (noted as $5 \mathrm{~mm}$ in one part of the manuscript and $5-10 \mathrm{~mm}$ in another) were deliberately left behind. They termed this partial removal as 'precision prostatectomy'.

A preliminary study of 100 radical prostatectomy samples was carried out, modelling the presence of cancer in the rim that would have been likely to be preserved with 'precision prostatectomy' and therefore what cancer would have been left behind after the new operation. This exercise suggested that $35 \%$ would have had cancer left behind, $14 \%$ having clinically significant disease. However, only 25 of these 100 cases would have been suitable for HIFU or focal therapy, which was one inclusion criterion for the ensuing pilot clinical study of eight men with good sexual function (four with Gleason $3+3$; four with $3+4$ disease). It is not clear from the paper how many of these 25 men would have had cancer left behind if they had undergone a 'precision prostatectomy'. It was surprising to me that routine postoperative mpMRI and modern imaging with PSMA PET-CT ${ }^{15}$ was not performed or reported.

At 12 months, the functional results were excellent with all men having good sexual function and continence. This compares with the authors' previous potency rates of $\sim 80 \%$ following standard RALP (although $~ 50 \%$ of the $80 \%$ used PGE-5 inhibitors).${ }^{16}$ As far as cancer outcomes are concerned, on the side of the "precision prostatectomy' positive margins were found in three men $(37.5 \%)$ including two of the four men with Gleason $3+4=7$ disease. These numbers are small, but in these men with $\leq \mathrm{cT} 2$ disease, they translate into positive margins in $50 \%$ of men with Gleason $3+4=7$ disease and $25 \%$ of men with Gleason $3+3=6$ disease, which may well seem concerning to many prostate surgeons. At a very early follow-up at 12 months, two men (25\%) had biochemical recurrence and had residual prostate volumes of $6 \mathrm{~mL}$ with positive biopsies. Both of the men with Gleason $3+4=7$ disease and positive margins had biochemical recurrence at 12 months. The authors describe this as satisfactory, but these outcomes would not generally be considered acceptable in a comparable contemporary surgical series, particularly given the short follow-up. ${ }^{12}$

We should applaud efforts to improve the functional outcomes of cancer surgery while preserving cancer recurrence rates, but unless a way can be found to accurately identify those men who truly do not have cancer near the fascia on the opposite side to the dominant lesion, such approaches may carry increased risks of local recurrence. Perhaps such procedures should be confined to only very low risk men, although the majority of such men do well without surgery.

Funding The authors have not declared a specific grant for this research from any funding agency in the public, commercial or not-for-profit sectors.

Competing interests None declared.

Patient consent for publication Not required.

Provenance and peer review Commissioned; internally peer reviewed.

Open access This is an open access article distributed in accordance with the Creative Commons Attribution Non Commercial (CC BY-NC 4.0) license, which permits others to distribute, remix, adapt, build upon this work non-commercially, and license their derivative works on different terms, provided the original work is properly cited, appropriate credit is given, any changes made indicated, and the use is non-commercial. See: http://creativecommons.org/licenses/by-nc/4.0/.

\section{REFERENCES}

1 Zhang L, Wu B, Zha Z, et al. Positive surgical margin is associated with biochemical recurrence risk following radical prostatectomy: a meta-analysis from high-quality retrospective cohort studies. World $\mathrm{J}$ Surg Oncol 2018;16:124.

2 Ahmed HU, El-Shater Bosaily A, Brown LC, et al. Diagnostic accuracy of multi-parametric MRI and TRUS biopsy in prostate cancer (PROMIS): a paired validating confirmatory study. The Lancet 2017;389:815-22.

3 Hamid S, Donaldson IA, Hu Y, et al. The SmartTarget biopsy trial: a prospective, within-person randomised, blinded trial comparing the accuracy of Visual-registration and magnetic resonance Imaging/ Ultrasound Image-fusion targeted biopsies for prostate cancer risk stratification. Eur Urol 2019;75:733-40.

4 Gnanapragasam VJ, Barrett T. The quest for the optimal prostate biopsy regime for the 21st century. Eur Urol 2019;75:741-2.

5 Padhani AR, Haider MA, Villers A, et al. Multiparametric magnetic resonance imaging for prostate cancer detection: what we see and what we miss. Eur Urol 2019;75:721-2.

6 Johnson DC, Raman SS, Mirak SA, et al. Detection of individual prostate cancer foci via multiparametric magnetic resonance imaging. Eur Urol 2019;75:712-20.

7 Cooper CS, Eeles R, Wedge DC, et al. Analysis of the genetic phylogeny of multifocal prostate cancer identifies multiple independent clonal expansions in neoplastic and morphologically normal prostate tissue. Nat Genet 2015;47:367-72.

8 Hamdy FC, Donovan JL, Lane JA, et al. 10-Year outcomes after monitoring, surgery, or radiotherapy for localized prostate cancer. $N$ Engl J Med 2016;375:1415-24.

9 Porten SP, Whitson JM, Cowan JE, et al. Changes in prostate cancer grade on serial biopsy in men undergoing active surveillance. $J$ Clin Oncol 2011;29:2795-800.

10 Haffner MC, De Marzo AM, Yegnasubramanian S, et al. Diagnostic challenges of clonal heterogeneity in prostate cancer. $J$ Clin Oncol 2015;33:e38-40.

11 Assel M, Dahlin A, Ulmert D, et al. Association between lead time and prostate cancer grade: evidence of grade progression from long-term follow-up of large population-based cohorts not subject to prostate-specific antigen screening. Eur Urol 2018;73:961-7.

12 Epstein JI, Egevad L, Amin MB, et al. The 2014 International Society of urological pathology (ISUP) consensus conference on Gleason grading of prostatic carcinoma: definition of grading patterns and proposal for a new grading system. Am J Surg Pathol 2016;40:244-52.

13 Gnanapragasam VJ, Bratt O, Muir K, et al. The Cambridge prognostic groups for improved prediction of disease mortality at diagnosis in primary non-metastatic prostate cancer: a validation study. BMC Med 2018;16:31.

14 Volanis D, Neal DE, Warren AY, et al. Incidence of needle-tract seeding following prostate biopsy for suspected cancer: a review of the literature. BJU Int 2015;115:698-704.

15 De Visschere PJL, Standaert C, Fütterer JJ, et al. A systematic review on the role of imaging in early recurrent prostate cancer. Eur Urol Oncol 2019;2:47-76.

16 Badani KK, Kaul S, Menon M. Evolution of robotic radical prostatectomy: assessment after 2766 procedures. Cancer 2007;110:1951-8. 